\title{
Effects of cigarette smoking on coagulation screening tests and platelet counts in a Sudanese male adults population
}

\author{
Ahmed M. Elkhalifa, MD, PhD.
}

\begin{abstract}
الأهداف : تقييم تأثير تدخين السجائر على تعداد الصفائح الدموية

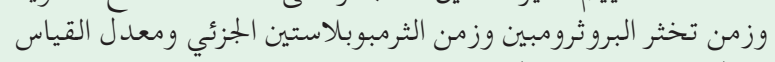
العالمي للسيولة لدى المدروندين وزمن المنين.

الطريقة: دراسة مقارنة أجريت في مدين السنتي كوستي والجبلين

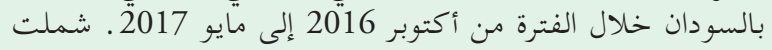

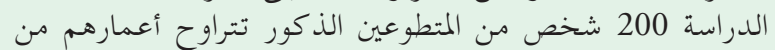

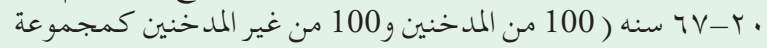

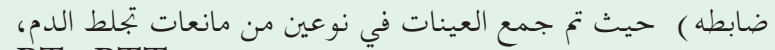

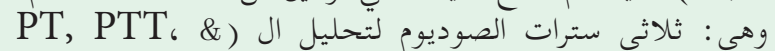

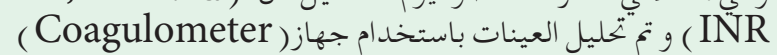

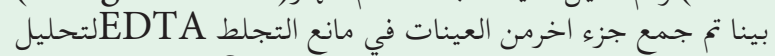

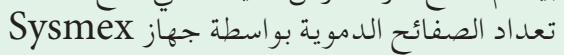

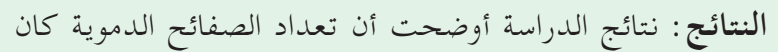

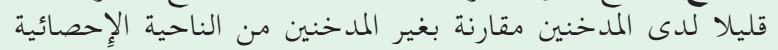

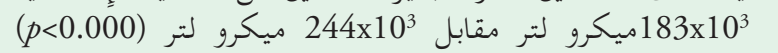

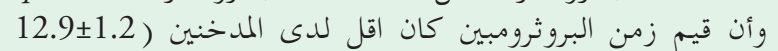

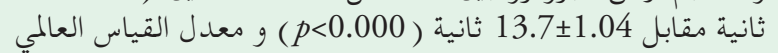

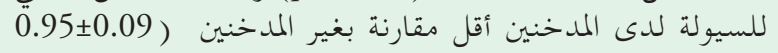

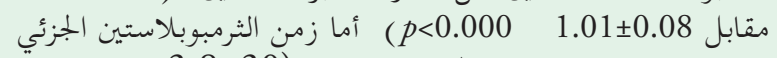

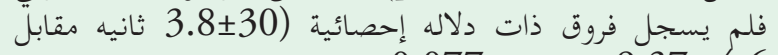

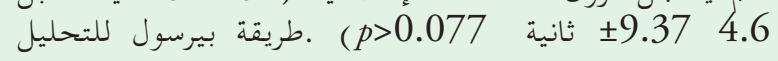

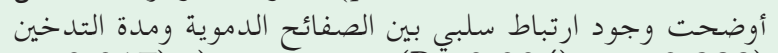

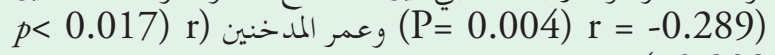
. $(=0.238$

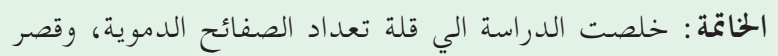

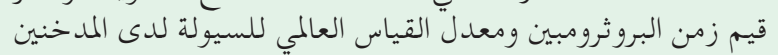
مقارنة مع غير المدخنين
\end{abstract}

Objectives: To study the effects of heavy cigarette smoking on coagulation (CGG) screening tests and platelet counts (PLTs) in a Sudanese male adults population.

Methods: A case control study was conducted at both Kosti and Gabalein towns, Sudan, during October
2016 to May 2017. A 100 adult cigarette smokers were selected and another 100 matched non-smokers were selected as healthy controls. Blood samples were collected in trisodium citrate anti-coagulant for prothrombin time (PT), partial thromboplastin time (PTT), and international normalized ratio (INR), analyzed using standard methods (co-agulometer machine) and Ethylenediaminetetraacetic acid for the platelet counts, using an automated haematology analyzer (Sysmex, Tokoyo, Japan).

Results: The results showed that the mean platelet counts were significantly lower in the smokers $\left(183 \times 10^{3} / \mathrm{cmm} \pm 64 \times 10^{3} / \mathrm{cmm}\right) \quad$ versus $\left(244 \times 10^{3} / \mathrm{cmm} \pm 38 \times 10^{3} / \mathrm{cmm}\right)$ in non-smokers, $(p<0.000)$. Pearson correlation analysis suggested a weak negative correlation between platelet counts with the duration of smoking $(r=-0.289, p<0.004)$ and the age of the smokers $(\mathrm{r}=-0.238, p<0.017)$. The mean PT and INR were also significantly lower in smokers $(12.9 \pm 1.2$ seconds) compared with the nonsmokers $(13.7 \pm 1.04$ seconds, $p<0.000)$, for PT and $(0.95 \pm 0.09$ versus $1.01 \pm 0.08, p<0.000)$ for INR. In contrast, PTT had no significant variation in smokers $(30.5 \pm 3.8$ seconds) and the non-smokers $(37.9 \pm 4.6$ seconds). A $p$-value $>0.05$ was considered significant.

Conclusion: Cigarette smokers tend to have lower platelet counts, shorter PT, and INR values, compared to non-smokers. Therefore, smoking might be associated with bleeding disorders but further investigations are needed.

Saudi Med J 2018; Vol. 39 (9): 897-901 doi: 10.15537/smj.2018.9.22630

From the Collage of Health Sciences, The Saudi Electronic University, Riyadh, Kingdom of Saudi Arabia, and from the Faculty of Medical laboratory Sciences, El Imam El Mahdi University, Kosti, Sudan.

Received 22nd May 2018. Accepted 8th August 2018.

Address correspondence and reprint request to: Dr. Ahmed M. Elkhalifa, The Saudi Electronic University, Riyadh, Kingdom of Saudi Arabia, E-mail: ahmedelnour2003@yahoo.com ORCID ID: orcid.org/0000-0002-2660-5054 
$\mathrm{C}$ igarette smoking could cause alterations in the main hemostatic systems, and coagulation factors which in turn could affect their functions. ${ }^{1}$ Hypotheses have been forward to explain the effect of tobacco smoking such as alteration clot structure and oxidative stress or the generation of procoagulant micro vesicles. ${ }^{2,3}$ Cigarette smoking exposure (CSE) elevates the risk of arterial thrombosis, approximately $40 \%$ of cigarette smoking-related deaths associated with cardiovascular disease. ${ }^{4}$ Some research demonstrated higher risk of thrombosis related to cardiomyocyte mitochondria oxidative damage and increased in smooth muscle cell proliferation and platelet aggregation. ${ }^{5-7}$ Cigarette smoking exposure effects on hemostasis have been documented in decreased expression tissue factor pathway inhibitor and increased smokers plasma fibrinogen levels compared to non-smokers. ${ }^{8,9}$ Few studies examined the effects of acute CSE on clotting, but circulating tissue factor activity increased levels have been demonstrated after short-term of cigarette smoking. ${ }^{9,10}$ So, CSE shows increasing prothrombotic biomarkers and might directly promote thrombosis.

Blood haemostasis can be affected by a variety of factors one of them is cigarette smoking which may cause many health problems. Scant information on hemostatic studies of smokers were observed in the Sudanese population especially in the study area, thus, the current study aimed to study the effects of heavy smoking (more than 5 cigarettes per day) on the prothrombin time (PT), partial thromboplastin time (PTT), platelet counts (PLT) counts and international normalized ratio (INR) test values and compare these parameters with the results obtained from those nonsmokers.

Methods. A case control study was carried out in 2 cities of Sudan, Kosti and Gabalein during October 2016 to May 2017. Two hundred male volunteers (100 cigarette smokers and 100 non-smokers as a control group) with ages between 20-67 years recruited to take place in this study. Smokers who had less than 3 years on smoking, history of alcoholism, presence of disease, which have a significant effect on coagulation, long-term medication, or current drugs, which have an effect on platelets and those who refused, were excluded from participation in the study. All the mentioned

Disclosure. Authors have no conflict of interests, and the work was not supported or funded by any drug company. criteria were applied for the non-smokers. Data was collected by using structural interviewing questionnaire. Venous blood specimens were collected in trisodium citrate anti-coagulant for PT, PTT, and INR, analyzed using standard methods (co-agulometer machine) and Ethylenediaminetetraacetic acid (EDTA) anticoagulant for the PLT counts, analyzed by (Sysmex, Tokyo, Japan) automated hematology analyzer.

Ethical considerations. According to Helsinki Declaration principles, prior to taking specimens, each participant completed the informed consent, which was approved by the Ethical and Research Committee of the University of El Imam El Mahdi, Faculty of Medical laboratory Sciences, Sudan and informed consent was taken.

Statistical analysis. Data analysis carried out by Statistical Package for the Social Sciences (SPSS) version 21 (IBM Corp., Armonk, NY, USA). Frequency distribution, mean, standard deviation and percentage were calculated. Test of normality carried out using normal distribution test to choose the suitable statistical test, so t-test applied for the comparison means to assess the difference between the 2 study groups. The two-tailed tests, alpha error of 0.05 and $p$-value $\leq 0.05$ were considered significant. Pearson correlation analysis was applied for correlation calculations between the study parameters.

Results. All participants were males (aged between 20-67 years old), as in the area where the current study was carried out females did not smoke cigarettes. This is due to socio-cultural causes; tobacco is used mostly by male rather than female. ${ }^{11}$ Table 1 shows smoked cigarettes per day and age comparison within the smokers group. Table 2 explains PT, PTT, PLTs, INR values of cigarette smokers, and non-smokers.

The mean PT is significantly shorter in smokers when compared to the non-smokers, $(12.9 \pm 1.15 \mathrm{~s}$ versus $13.7 \pm 1.04 \mathrm{~s}(p<0.000)$, whereas the mean APTT is not statistically significant between smokers and non-smokers $(30.5 \pm 3.8$ s versus $37.9 \pm 4.6 s),(p<0.077)$. Platelet count is statistically significantly lower in the smokers $(183 \pm 64 / \mu \mathrm{l}$ versus $244 \pm 376 / \mu \mathrm{l}(p<0.000)$.

Table 1 - Smoked cigarettes per day and age comparison within the smokers group.

\begin{tabular}{lclc}
\hline Smoked cigarettes per day $(\%)$ & \multicolumn{2}{c}{ Age (\%) } \\
\hline 5 to 9 & $(39)$ & $3-5$ years & $(31)$ \\
10 to 15 & $(38)$ & $6-10$ years & $(27)$ \\
$>15$ & $(23)$ & $>10$ years & $(42)$ \\
\hline
\end{tabular}


Table 2 - The PT, PTT, PLTs count, INR values of cigarette smokers versus nonsmokers.

\begin{tabular}{|c|c|c|c|c|c|c|c|}
\hline \multirow[t]{2}{*}{ Parameter } & \multicolumn{3}{|c|}{ Cigarette Smokers n=100 } & \multicolumn{3}{|c|}{ Non-cigarette Smokers n=100 } & \multirow[b]{2}{*}{$P$-value } \\
\hline & Category (values) & Frequency & Mean \pm SD & Category (values) & Frequency & Mean \pm SD & \\
\hline \multirow{4}{*}{$\mathrm{PT}(\mathrm{s})$} & $10-10.9 \mathrm{~s}$ & 3 & & \multirow{2}{*}{$12.1-14 \mathrm{~s}$} & \multirow{3}{*}{65} & \multirow{4}{*}{$13.7 \pm 1.04^{*}$} & \multirow{4}{*}{$0.000^{*}$} \\
\hline & $11-13.5 \mathrm{~s}$ & 70 & $129+115 *$ & & & & \\
\hline & $13.6-16 \mathrm{~s}$ & 25 & $12.9 \pm 1.15 \mathrm{~s}^{*}$ & \multirow{2}{*}{$14.1-16 \mathrm{~s}$} & & & \\
\hline & $16.1-17 \mathrm{~s}$ & 2 & & & 35 & & \\
\hline \multirow{5}{*}{ APTT(s) } & $19-23 \mathrm{~s}$ & 3 & & \multirow{2}{*}{$27-29.9 s$} & 12 & \multirow{5}{*}{$37.9 \pm 4.6 \mathrm{~s} \ddagger$} & \multirow{5}{*}{0.077} \\
\hline & $23.1-27 s$ & 11 & & & 37 & & \\
\hline & $27.1-29.9 s$ & 31 & $30.5 \pm 3.8 \mathrm{~s} \ddagger$ & \multirow{2}{*}{$30-34 s$} & \multirow{3}{*}{15} & & \\
\hline & $30-34.9 \mathrm{~s}$ & 41 & & & & & \\
\hline & $35-40 s$ & 14 & & $34.1-39 \mathrm{~s}$ & & & \\
\hline \multirow{4}{*}{ PLTs $/ \mu \mathrm{l}$} & $<150 \times 10^{3} / \mathrm{cmm}$ & 34 & & $164-230 \times 10^{3} / \mathrm{cmm}$ & 38 & \multirow{6}{*}{$\begin{array}{c}244 \pm 376 \times 10^{3} / \\
\mathrm{cmm}^{*}\end{array}$} & \multirow{4}{*}{$0.000^{*}$} \\
\hline & $\begin{array}{c}151-250 \times 10^{3} / \\
\mathrm{cmm}\end{array}$ & 51 & & $231-290 \times 10^{3} / \mathrm{cmm}$ & 49 & & \\
\hline & $\begin{array}{c}251-350 \times 10^{3} / \\
\mathrm{cmm}\end{array}$ & 12 & $183 \pm 64 \times 10^{3} / \mathrm{cmm}^{*}$ & \multirow[b]{2}{*}{$291-350 \times 10^{3} / \mathrm{cmm}$} & \multirow[b]{2}{*}{13} & & \\
\hline & $\begin{array}{c}351-450 \times 10^{3} / \\
\mathrm{cmm}\end{array}$ & 3 & & & & & \\
\hline \multirow{2}{*}{ INR } & $0.7-0.8$ & 34 & \multirow{2}{*}{$0.95 \pm 0.09$} & $0.80-0.95$ & 36 & & \\
\hline & $0.81-0.9$ & 51 & & $0.96-1.05$ & 30 & & \\
\hline
\end{tabular}

Table 3 - Pearson correlation between age, duration, and number of cigarette per day with the coagulation parameters (PT, PTT, PLTs and INR) among cigarette smokers.

\begin{tabular}{lcc}
\hline Category & Pearson correlation & $P$-value \\
\hline Age & & \\
PLT & -0.238 & 0.017 \\
PT & -0.039 & 0.699 \\
PTT & 0.041 & 0.689 \\
INR & 0.013 & 0.900 \\
Duration & \\
INR & 0.116 & 0.250 \\
PLT & -0.289 & 0.004 \\
PTT & 0.089 & 0.378 \\
PT & 0.089 & 0.806 \\
Number & & \\
PT & -0.044 & 0.663 \\
PTT & 0.112 & 0.268 \\
PLT & -0.132 & 0.192 \\
INR & -0.005 & 0.961 \\
\hline \multicolumn{2}{c}{ PT - prothrombin time, APTT - activated partial } \\
thromboplastin time, PLTs - platelet counts, SD - standard \\
\multicolumn{2}{c}{ deviation, INR - international normalized ratio } \\
\hline \multicolumn{2}{c}{}
\end{tabular}

Table 3 summarizes the correlation and significance between age, duration, and number per day with the coagulation parameters (PT, PTT, PLTs and INR) among cigarette smokers.

The findings of the current study observed that the highest number of cigarette smokers in this study was in the 20-30 years age range, however the relationship between the 4 age groups of smokers (20-30 years), (31-40 years), (41-50 years) and ( $>50$ years) and PT, PTT, and INR parameters showed no significant differences $(p>0.05)$; but there was a significance relationship between age and PLTs $(\mathrm{r}=-0.238, p<0.017)$, this indicated that cigarette smoking was a significant public health problem among youths.

Discussion. Hypercoagulability state could be caused by cigarette smoking, potentially leading to thrombosis. ${ }^{12}$ Cigarette smoking appears to play a significant role in coagulation factors malfunctions. ${ }^{13,14}$ The current study was conducted to know the effects of heavy cigarette smoking on PTT, PT, PLTs and INR among cigarette smokers in Kosti and Gabalein, Sudan. The present study findings state that, the mean PLT was statistically significantly lower with smokers $(183 \pm 64 / \mu \mathrm{l}$ versus $244 \pm 376 / \mu \mathrm{l}, p<0.000)$. This result was in the line with the ROA Mustafa study, ${ }^{15}$ that, smoking significantly reduced platelet count $(212.30 \pm 55.71$ vs. $\left.238.23 \pm 36.89 \times 10^{9} / 1\right)$ and previous study carried out by Metta $S$ et al, ${ }^{16}$ in 2015 reported that, platelet count was significantly lower in chronic smokers. The current results was not in agreement with the findings stated by Ghahremanfard et al, ${ }^{17}$ who concluded that, the mean platelet count was significantly higher in adult smokers than in adult non-smokers and Al-Dahr study, ${ }^{18}$ reported 
that, no significant difference between adult smokers and non-smokers regarding platelet count. Concerning PT the current study revealed that, the mean PT was significantly shorter in smokers when compared to the non-smokers, $(12.9 \pm 1.15 \mathrm{~s}$ versus $13.7 \pm 1.04 \mathrm{~s}$, $p<0.000)$, the significantly reduced PT value was agreed with the results obtained by Akpotuzor et al, ${ }^{19}$ who reported that, mean prothrombin time values of smokers were significantly lower when compared with the non-smokers and disagree with the findings obtained from the study carried out by Metta $S$ et.al, ${ }^{16}$ who showed that no significant difference in PT, on the other hand the current study results regarding PT value inconsistent with the results of Al-Dahr study, ${ }^{18}$ who reported that PT was not changed significantly in the smoker groups. Regarding the results of the APTT there is no statistically significant difference between smokers and non-smokers $(30.5 \pm 3.8$ s versus $37.9 \pm 4.6$ s, $p<0.077)$ in the current study, however the results recorded by Akpotuzor et al, ${ }^{19}$ showed that mean APTT values of smokers were significantly lower $(p<0.01)$ when compared with the non-smokers. According to the present study findings, the mean of INR was significantly shorter in smokers when compared to the non-smokers, $(0.95 \pm 0.09$ versus $1.01 \pm 0.08, p<0.000)$. This findings were agreed with a previous study reported by Nascetti et al, ${ }^{20}$ who argued that, the decrease in INR value associated with cigarette smoking is proportional to the number of cigarette smoked per day. Pearson correlation analysis suggested a weak negative correlation between platelet count with the duration of smoking $(r=-0.289, p<0.004)$, these findings were not in agreement with the study carried out by Metta $S$ et.al, ${ }^{16}$ their Pearson correlation analysis suggested a strong negative correlation between platelet count with the duration of smoking. The decrease in platelet count could be due to nicotine-induced decreased thrombopoietic activity in smokers. ${ }^{21}$ The findings of the current study observed that the highest number of cigarette smokers in this study was in the 20-30 years age range, however the relationship between the 4 age groups of smokers (20-30 years), (31-40 years), (41-50 years) and (>50 years) and PT, PTT, and INR parameters showed no significanct difference $(p>0.05)$; but there was a significant relationship between age and PLTs count $(\mathrm{r}=-0.238, p<0.017)$, which indicated that cigarette smoking to be a concerned public health problem among youths. The participants are from only one state of the 18 states in Sudan.

In conclusion, cigarette smokers tend to have lower platelet counts, shorter PT, and INR values, compared to non-smokers so, the efforts need for governmental and non-governmental organizations (NGOs), and clinicians to develop public awareness to mitigate the risk of cigarette smoking targeted at youths.

Acknowledgment. The author would like to thank his colleagues, all the participants in this study and Al-Amri office for English language editing.

\section{References}

1. Barua RS, Ambrose JA. Mechanisms of coronary thrombosis in cigarette smoke exposure. Arterioscler Thromb Vasc Biol 2013; 33: 1460-1467.

2. Kooij KW, Wit FW, Booiman T, van der Valk M, Schim van der Loeff MF, Kootstra NA, et al. Cigarette Smoking and Inflammation, Monocyte Activation, and Coagulation in HIV-Infected Individuals Receiving Antiretroviral Therapy, Compared With Uninfected Individuals. J Infect Dis 2016; 214: 1817-1821.

3. Li CJ, Liu Y, Chen Y, Yu D, Williams KJ, Liu ML. Novel proteolytic microvesicles released from human macrophages after exposure to tobacco smoke. Am J Pathol 2013; 182: 1552-1562.

4. Ho JY, Elo IT. The contribution of smoking to black-white differences in U.S. mortality. Demography 2013; 50: 545-568.

5. Al Rifai M, DeFilippis AP, McEvoy JW, Hall ME, Acien AN, Jones $\mathrm{MR}$, et al. The relationship between smoking intensity and subclinical cardiovascular injury: The Multi-Ethnic Study of Atherosclerosis (MESA). Atherosclerosis 2017; 258: 119-130.

6. Pamukcu B, Oflaz H, Onur I, Cimen A, Nisanci Y. Effect of cigarette smoking on platelet aggregation. Clin Appl Thromb Hemost 2011; 17: E175-E180.

7. Wylam ME, Sathish V, VanOosten SK, Freeman M, Burkholder D, Thompson MA, et al. Mechanisms of Cigarette Smoke Effects on Human Airway Smooth Muscle. PLoS One 2015; 10: $\mathrm{e} 0128778$.

8. Barua RS, Ambrose JA, Saha DC, Eales-Reynolds LJ. Smoking is associated with altered endothelial-derived fibrinolytic and antithrombotic factors: an in vitro demonstration. Circulation 2002; 106: 905-908.

9. Kawase Ishihara K, Kokubo Y, Yokota C, Hida E, Miyata T, Toyoda K, et al. Effect of Plasma Fibrinogen, High-Sensitive C-Reactive Protein, and Cigarette Smoking on Carotid Atherosclerosis: The Suita Study. J Stroke Cerebrovasc Dis 2015; 24: 2385-2389.

10. Kohashi K, Nakagomi A, Morisawa T, Endoh I, Kawaguchi N, Kusama Y, et al. Effect of Smoking Status on Monocyte Tissue Factor Activity, Carotid Atherosclerosis and Long-Term Prognosis in Metabolic Syndrome. Circ J2018; 82: 1418-1427.

11. Spaulding AC, Eldridge GD, Chico CE, Morisseau N, Drobeniuc A, Fils-Aime R, et al. Smoking in Correctional Settings Worldwide: Prevalence, Bans, and Interventions. Epidemiol Rev 2018; 40: 82-95.

12. Sambola A, Osende J, Hathcock J, Degen M, Nemerson Y, Fuster V, et al. Role of risk factors in the modulation of tissue factor activity and blood thrombogenicity. Circulation 2003; 107: 973-977.

13. Csordas A, Bernhard D. The biology behind the atherothrombotic effects of cigarette smoke. Nat Rev Cardiol 2013; 10: 219-230. 
14 Frayn KN, Williams CM, Arner P. Are increased plasma nonesterified fatty acid concentrations a risk marker for coronary heart disease and other chronic diseases? Clin Sci (Lond) 1996; 90: 243-253.

15. Mustafa, ROA. Estimation of complete blood cells count in Sudanese cigarette smokers in Khartoum North [dissertation]. Khartoum; SUST; 2017. Accessed [17 March 2018]. Available from: http://repository.sustech.edu/ bitstream/handle/123456789/19626/Estimation\%20of\%20 Complete $\% 20$ Blood.......pdf? sequence $=1$

16. Metta S, Uppala S, Mohanty S, Basalingappa DR. Impact of chronic cigarette smoking on platelet aggregation and coagulation profile in apparently healthy male smokers. International journal of clinical and experimental physiology 2015; 2: 128-133.

17. Ghahremanfard F, Semnani V, Ghorbani R, Malek F, Behzadfar A, Zahmatkesh M. Effects of cigarette smoking on morphological features of platelets in healthy men. Saudi Med J 2015; 36: 847-850.
18. Al-Dahr MH. Impact of Smoking on Platelet, Coagulation and Lipid Profile in Young Male Subjects. World Applied Sciences Journal 2010; 11: 118-123.

19. Akpotuzor JO, Inyama MA, Agwunobi LE. Prothrombin time and partial thromboplastin time test values of cigarette smokers in Calabar, cross-river state, Nigeria. Advances in Medical and Dental Sciences 2009; 3: 17-20.

20. Nascetti S, Elosua R, Pena A, Covas MI, Senti M, Marrugat J, et al. Variables associated with fibrinogen in a population-based study: interaction between smoking and age on fibrinogen concentration. Eur J Epidemiol 2001; 17: 953-958.

21. Biljak VR, Pancirov D, Cepelak I, Popović-Grle S, Stjepanović G, Grubišić TŽ. Platelet count, mean platelet volume and smoking status in stable chronic obstructive pulmonary disease. Platelets 2011; 22: 466-470.

\section{Authorship entitlement}

Excerpts from the Uniform Requirements for Manuscripts Submitted to Biomedical Journals updated November 2003.

Available from www.icmje.org

The international Committee of Medical Journal Editors has recommended the following criteria for authorship; these criteria are still appropriate for those journals that distinguish authors from other contributors.

Authorship credit should be based on 1) substantial contributions to conception and design, or acquisition of data, or analysis and interpretation of data; 2) intellectual content; and 3) final approval of the version to be published. Authors should meet conditions 1,2 , and 3 .

Acquisition of funding, collection of data, or general supervision of the research group, alone, does not justify authorship.

An author should be prepared to explain the order in which authors are listed. 